\title{
Structural Changes in the Surface Layer of Deep Rolled Samples Due to Thermal Loads
}

\author{
Strunk, R.; Clausen, B.; Zoch, H.-W.
}

\begin{abstract}
Deep rolling processes initiate plastic deformations in the surface layer. The local characteristics of deformation are dependent on the induced stress expressed by the local stress tensor. Equivalent stresses above yield strength cause plastic deformation. Additionally the intrinsic energy, e. g. the dislocation density, is enhanced and the residual stress state is changed. The effects to a deep rolled surface from an increase in temperature are mainly dependent on the material, the microstructure, the initial residual stress state, the inclusion density, the distribution of soluted alloying elements and the plastic deformation. In the described experiments the interactions between deformation and temperature of the steel grade AISI 4140 (42 CrMo 4) used for all further experiments in a transregional Collaborative Research Center (CRC) were to be examined. The most simple investigation methods were chosen deliberately to allow a better statistical support of correlations between introduced strains and material reactions for a wide variation of process parameters. Since the visual effects by light microscopy in AISI 4140 were very s mall, the experiments were repeated with german grade $18 \mathrm{CrNiMo}$ 7-6 (comparable to AISI 4820). This paper focuses on the mic ro structural changes in defined deep rolled surface regions due to an increase in temperature. The work described is part of the Collaborative Research Center "Process Signatures", collaboration between Bremen University, Technical University Aachen, Germany and Oklahoma State University Stillwater, USA.
\end{abstract}

Keywords: surface modification, machining, deep rolling

\section{INTRODUCTION}

The subproject M02 "Mechanism analys is of material modifications caused by thermal and mechanical loads" of the CRC "Process signatures" aims to explain the interactions between deformation and temperature influences that may occur in machining operations. In literature several works concerning the influence of deformation and annealing treatments on residual stresses and the microstructure for various metals can be found. The most accurate results have been determined with residual stress measurements and TEM analysis of the dislocation distribution in the influenced areas. However, if a great number of material variations are to be compared, it is desirable to apply a less sophisticated but faster investigation method. In this paper the possibilities of common light microscopy are worked out. To be able to assess the visible changes in microstructure after deforming and annealing processes it is necessary to produce defined reference samples and investigate the changes detectable in dependence of load and temperature. Annular samples of the steel batch 42 CrMo 4 (AISI 4140, FP-annealed), used in the CRC were produced and deep rolled in an ECOROLL ${ }^{\circledR}$ testing device. Though the maximum pressure in the contact area increased up to 4.490 $\mathrm{MPa}$ almost no changes in this steel could be observed in the microscope. To enhance the visibility of effects the experiments were repeated with an alloy with minor carbon content (18CrNiMo7-6; AISI 4820). As a further investigation method the hardness measurement in the cross section with a nanoindenter was applied.

\section{STATE OF THE ART}

The surface pressure created in the contact zone between workpiece and tool due to deep rolling causes a triaxial stress state, changing with the distance from surface. The stress state can be described as a contact between a sphere a cylinder (Hertzian pressure). Figure 1 shows the geometrical conditions in the contact area.

The calculation of the stress state from the maximum contact pressure results in a maximum equivalent stress beneath the surface. The elastic deformations of the contact zone as well as the depth and amount of maximum equivalent stress can be calculated with the Hertzian solution for the elastic contact [3]. Starting from the Hertz 's equations Föppl calculated the load stresses below the contact surface for different geometries [4]. Mesys provides a good working online tool to calculate the elastic stress distribution, the depth and amount of the maximum shear stress for different geometries in the contact area [1]. 


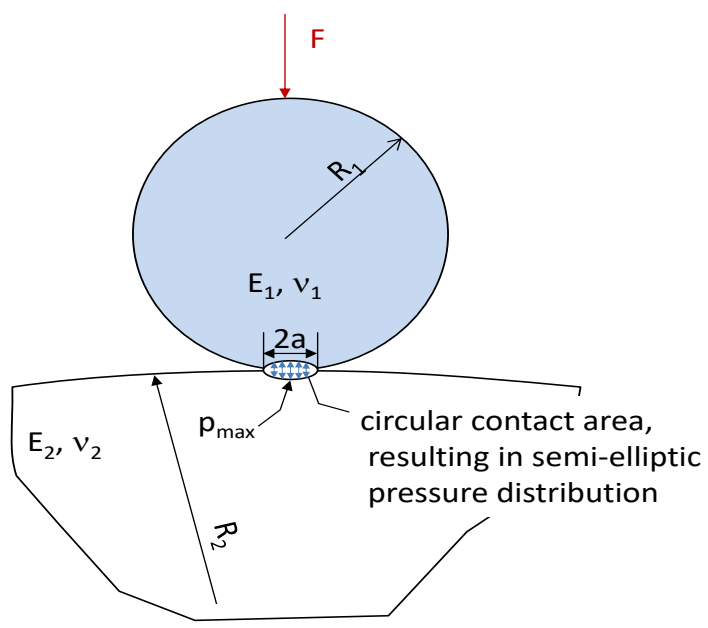

Figure 1: Geo metrical conditions in the contact area of a sphere pressed onto a cylinder

If the maximum equivalent stress increases the yield strength of the material, plastic deformation occurs. Local plastic deformation causes a change in the microstructure and the residual stress state. However, equivalent stresses below yield strength also provoke a change in the condition of the surface layer [2]. The influence of deep rolling on the residual stress state and the microstructure is described in detail by various authors [e.g. 5, 6, 7, 8]. Results have been depicted by measurements of residual stress and the full width at half maximum of the X-ray interference lines (FWHM) depth profiles and TEMmicrographs of selected areas in the surface. The deformation results in compressive residual stresses in the surface area. The level of these compressive stresses and the decrease with distance from surface is dependent on the condition of the initial state of the material and the rolling force and contact geometry. TEM micrographs show a strong increase in the dislocation density. Lu finds out that in contrast to shot peened samples, the dislocations in deep rolled samples tend to cells formation [6].

The named investigation methods have the advantage of high accuracy. On the other hand only very small areas of the treated samples can be investigated. Since in the CRC many samples and variations have to be compared this work aims to investigate less sophisticated methods to rate the surface conditions of machined surfaces in order to be able to assess larger surface regions for a better statistical support for a lot of parameter variations.

\section{APPROACH}

To investigate the possibility to investigate various thermo-mechanical treatments in a large surface area annual rings machined from the standard CRC-steel batch (42 CrMo 4 (AISI 4140), FP-annealed) and a case hardening steel (18 CrNiMo 7-6, (AISI 4820), FP-annealed) were deep rolled in an Ecoro $1 l^{\circledR}$ testing device with three different loads (corresponding to maximum elastic contact pressures of 3 390, 3990 and $4420 \mathrm{MPa}$ ) and partly heat treated. Cross sections of these rings were examined metallographically and by nanoindentation.

The chemical composition of the materials investigated is given in table 1 . The 4140 steel was investigated in the FP-annealed state. The annealing curve for the applied heat treatment is given in figure 2 .

Table 1: Chemical composition of the materials (in mass-\%)

\begin{tabular}{|l|l|l|l|l|l|l|}
\hline Steel grade & C & Cr & Ni & Mo & Si & Mn \\
\hline $\begin{array}{l}\text { AISI 4140 } \\
\text { 42 CrMo 4 }\end{array}$ & 0.43 & 1.09 & -- & 0.25 & 0.26 & 0.74 \\
\hline $\begin{array}{l}\text { AISI 4820 } \\
\begin{array}{l}18 \text { CrNiMo } \\
7-6\end{array}\end{array}$ & 0.19 & 1.63 & 1.43 & 0.287 & 0.31 & 0.52 \\
\hline
\end{tabular}

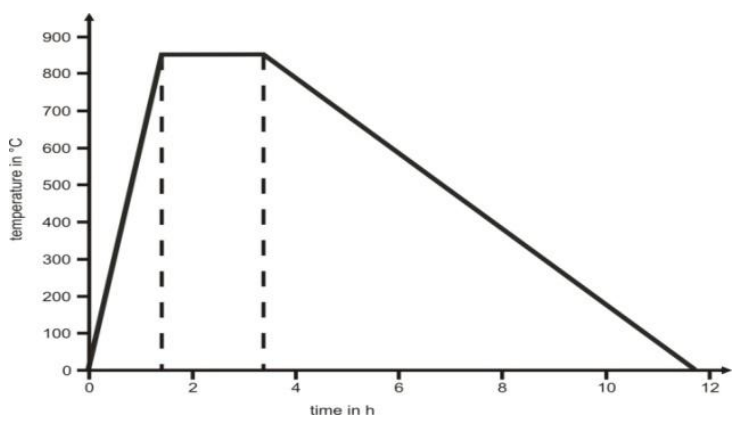

Figure 2: Time-temperature-diagram for ferritepearlite annealing for AISI 4140 steel

The 4820 grade was delivered in a ferritepearlite annealed state. For the experiments rings with an inner diameter of $28 \mathrm{~mm}$ and an outer diameter of $46 \mathrm{~mm}$ (height $20 \mathrm{~mm}$ ) were prepared. The rings were assembled in an Ecoroll ${ }^{\circledR}$ testing device (figure 3 ). The deep-rolling tools were equipped with $6 \mathrm{~mm}$ ceramic balls. The rings were deep-rolled at the outer diameter with three different pressures, namely $30 \mathrm{bar}, 50 \mathrm{bar}$ and 70 bar. The operating normal force cannot be calculated directly from the hydraulic pressure in the device due to oil spill. It was extrapolated from force measurements in a range between 100 and 400 bar in a deep rolling device with the same ball diameter to 85,140 and $190 \mathrm{~N}$.

The corresponding maximum contact pressures, the maximum shear stress and the depth of the appearance of this stress were calculated with an online tool [1] for simplified elastic conditions. The results are summarized in table 2 . 


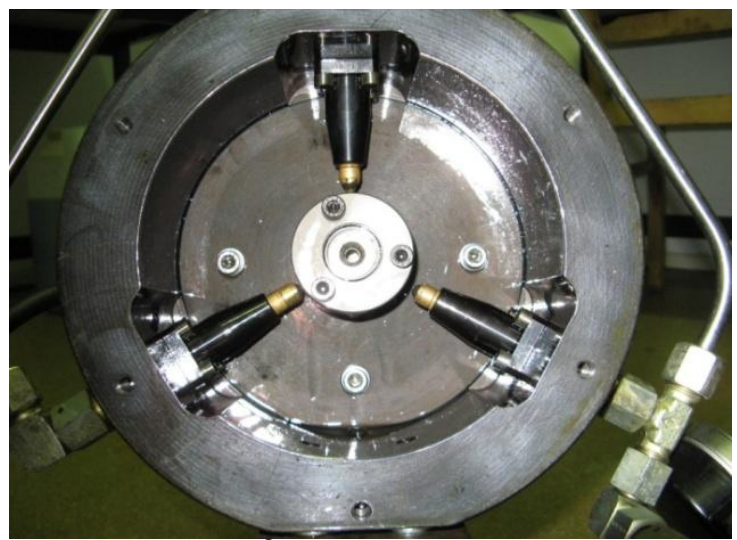

Figure 3: Ecoroll $^{\circledR}$-testing device for deep rolling of annular samples

Table 2: Hert zian stress and subsurface stresses calculated for elastic contact between ceramic ball $(\varnothing=6 \mathrm{~mm})$ and cylinder $(\varnothing=46 \mathrm{~mm})$

\begin{tabular}{|l|l|l|l|}
\hline $\begin{array}{l}\text { normal } \\
\text { force }\end{array}$ & $\begin{array}{l}\text { max. contact } \\
\text { pressure } \\
\mathrm{p}_{0}\end{array}$ & $\begin{array}{l}\text { max. shear } \\
\text { stress } \\
\tau_{\max }\end{array}$ & $\begin{array}{l}\text { depth } \\
\left(\tau_{\max }\right) \\
\text { in ring }\end{array}$ \\
\hline $\mathrm{N}$ & $\mathrm{MPa}$ & $\mathrm{MPa}$ & $\mu \mathrm{m}$ \\
\hline 190 & 4420 & 1382 & 69 \\
\hline 140 & 3990 & 1247 & 62 \\
\hline 85 & 3390 & 1058 & 53 \\
\hline
\end{tabular}

Subsequent to the deep-rolling process the rings were separated into eight segments by electric discharge machining. Seven segments underwent annealing for one hour at temperatures between $200{ }^{\circ} \mathrm{C}$ and $800{ }^{\circ} \mathrm{C}$. Afterwards the segments were prepared for metallographic analysis. As the visual effects in the 4140 were very small the procedure was repeated with the 4820 .

The hardness measurement was carried out with a Fischerscope H100C hardness measurement device. Beneath the deep rolled tracks scans of Martens hardness values were acquired and averaged over the depth.

\section{RESULTS}

\section{Metallographic investigation}

Micrographs of the cross sections of the deep rolled tracks on 4140 steel are compared in figure 4. Only a very thin deformed layer can be depicted at the surface of the samples. However this thin layer is also visible on the not deep rolled surface, depicted here in the very left micrograph, which implies that it is caused by former machining operations. The maximum shear stresses do not cause any visible changes in the surface near regions.

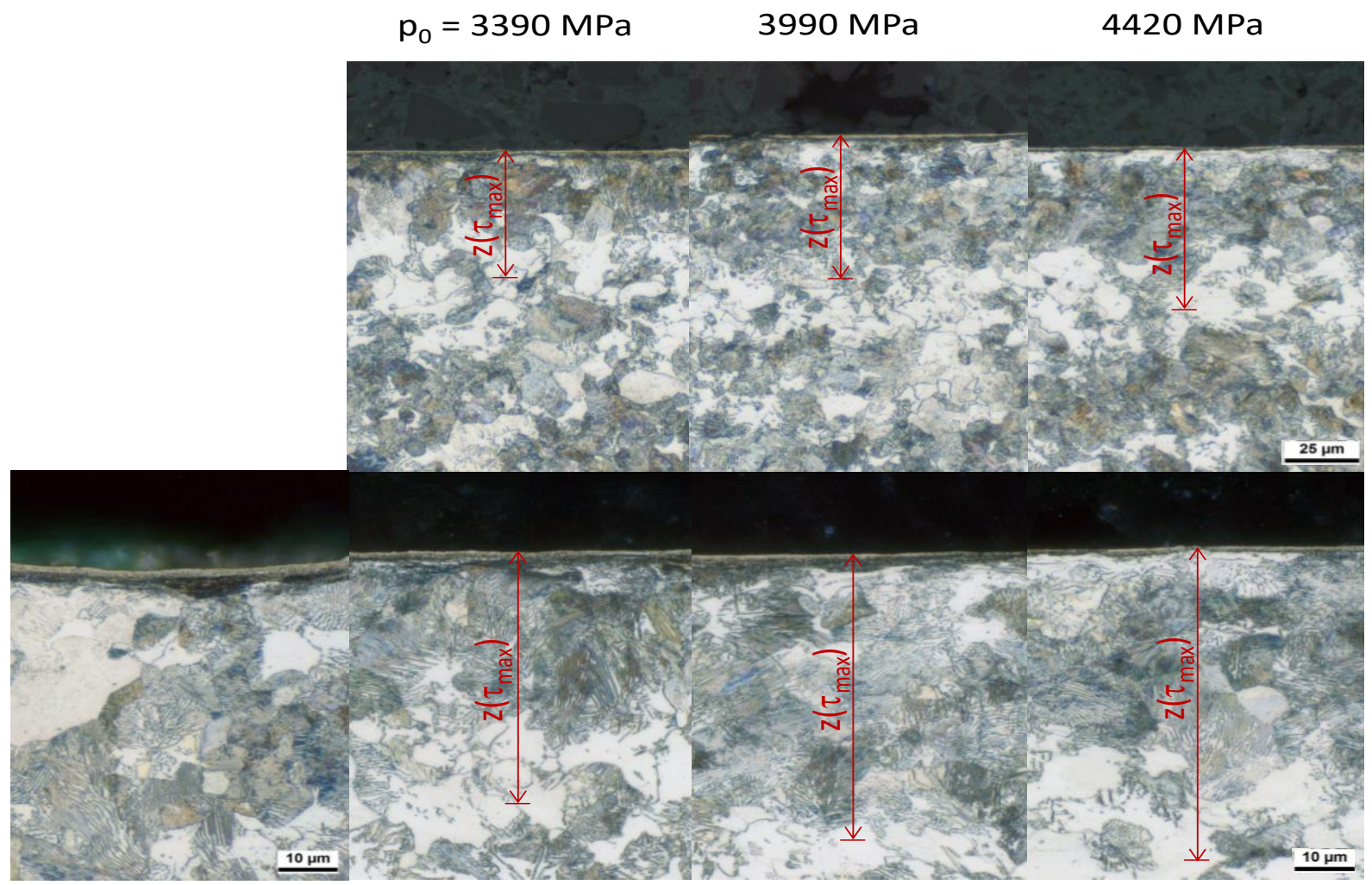

Figure 4: Comparison of metallographic cross sections of deep rolled tracks (steel 4140, FP-annealed), left: unaffected surface 
Still, the acting stresses will have caused changes not visible in the microscope. Another possibility to depict changes due to plastic deformation is the recrystallization of a deformed microstructure, since the stored intrinsic energy may cause a development of new crystals. In the following figures only the high resolutions of the micrographs are shown since the interesting microstructures are visible in the first $70 \mu \mathrm{m}$.
Figure 5 compares the microstructure beneath the deep rolled tracks after an annealing treatment at $600{ }^{\circ} \mathrm{C}$ for 1 hour. At contact pressures of 3990 and $4420 \mathrm{MPa}$ in the direct surroundings of the depth of the occurrence of the maximum shear stress small ferritic islands can be found. Still, the differences to the unaffected microstructure are too small to use this effect as an indicator.

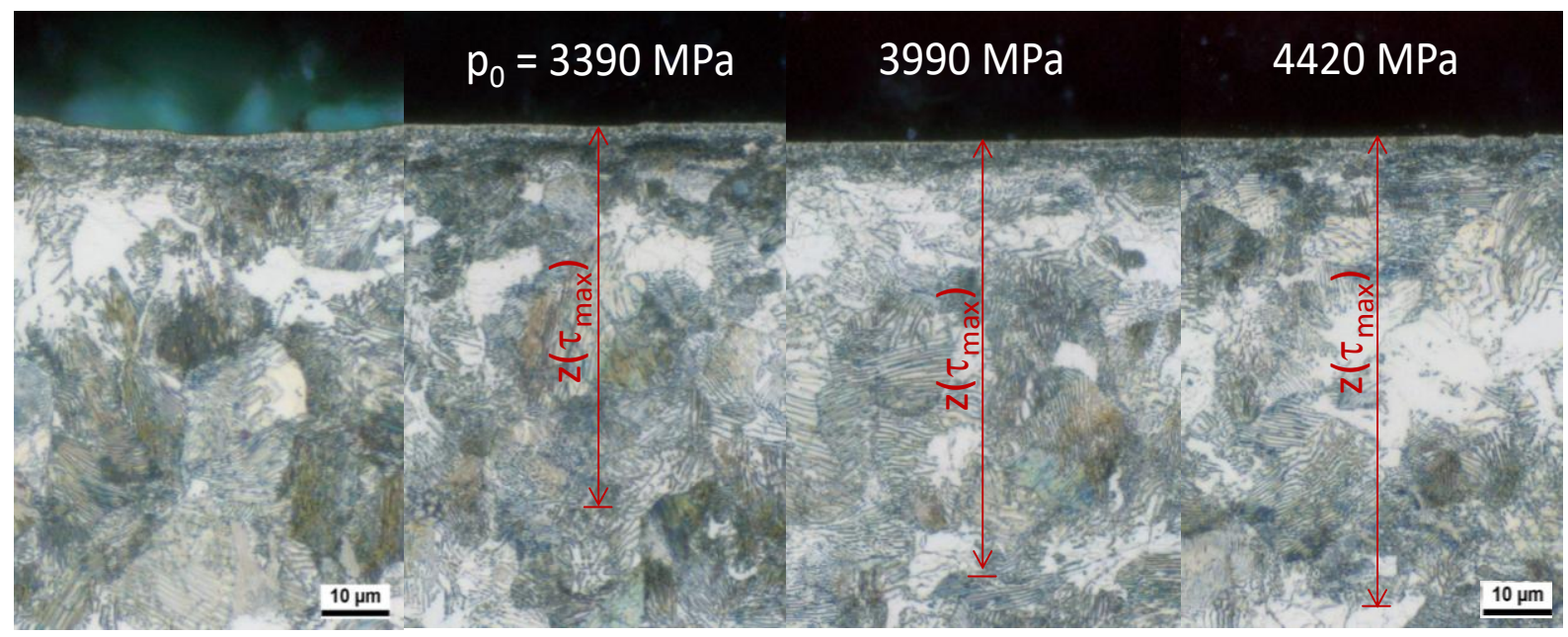

Figure 5: Comparis on of metallographic cross sections of deep rolled tracks (steel 4140, FP-annealed) after tempering at $600{ }^{\circ} \mathrm{C}$ for 1 hour, left: unaffected surface

After an annealing treatment at $700{ }^{\circ} \mathrm{C}$ the changes are a bit more obvious (Figure 6). The deformed layer in the very surface has recrystallized to a very fine grained seam. The deformed regions beneath the deep rolled tracks show a fine grained structure in the ferritic microstructure at the depth of maximum shear stresses and at smaller depths for contact stresses of 3990 and $4420 \mathrm{MPa}$. Changes are only visible in the ferritic grains of the microstructure. At 3390 MPa no visible changes occur. The minor changes in the micro structure raised the question if the forces are still too small to show a visible effect or if there are other reasons. Furthermore it was of interest how stronger deformations could lead to more pronounced micro structure changes after annealing. AISI 4820 as a steel with lower carbon content was chosen to complete the investigations.

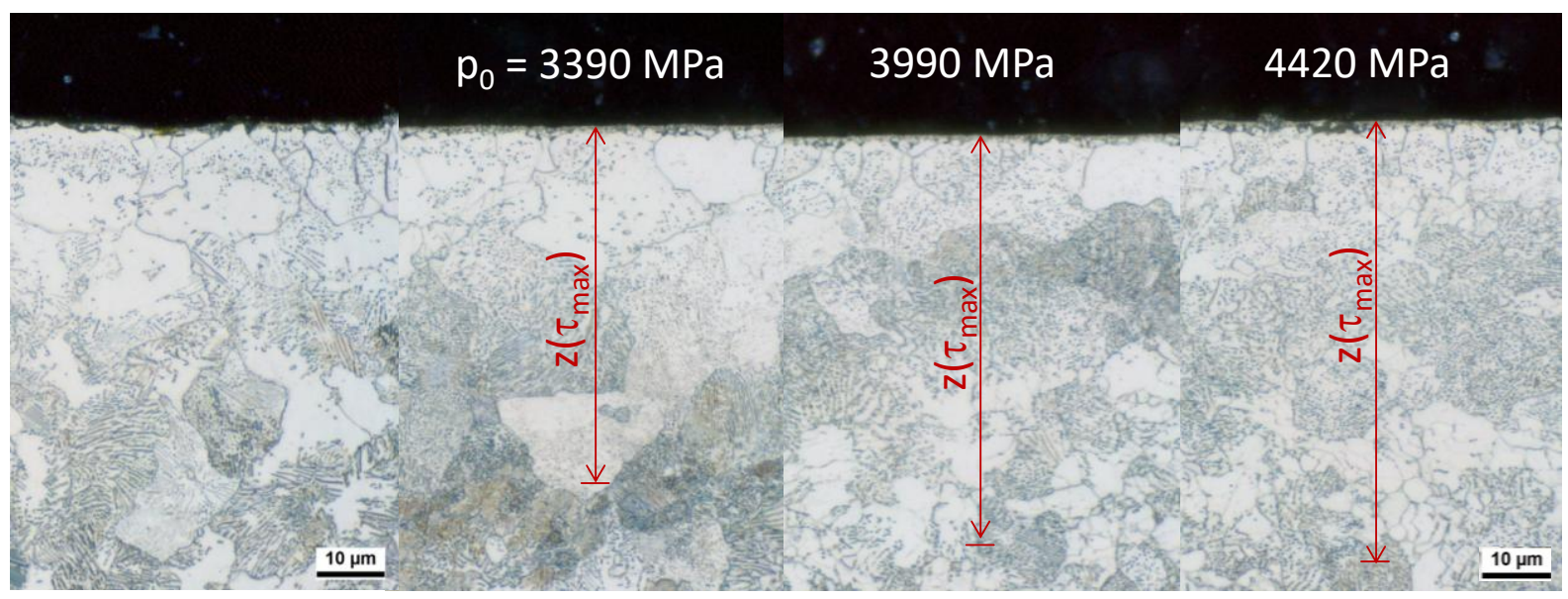

Figure 6: Comparis on of metallographic cross sections of deep rolled tracks (steel 4140, FP-annealed) after tempering at $700{ }^{\circ} \mathrm{C}$ for lhour, left: unaffected surface 
Figure 7 compares the microstructure beneath the deep rolled tracks on steel 4820 . With a maximum elastic contact stress of $3390 \mathrm{MPa}$ no visible microstructure changes can be detected. At contact stresses of 3990 and $4420 \mathrm{MPa}$ increasing deformation can be observed. The deformation increases up to the calculated depth of the maximum shear stress. In Figure 8 and 9 the microstructure of the deep rolled tracks is shown after annealing at 300 and $500{ }^{\circ} \mathrm{C}$. As expected no changes in the microstructure are detectable. After annealing with $600{ }^{\circ} \mathrm{C}$ recrystallized grains are detected in the tracks deep rolled with a maximum contact stress of 3990 and $4420 \mathrm{MPa}$ (Figure 10).

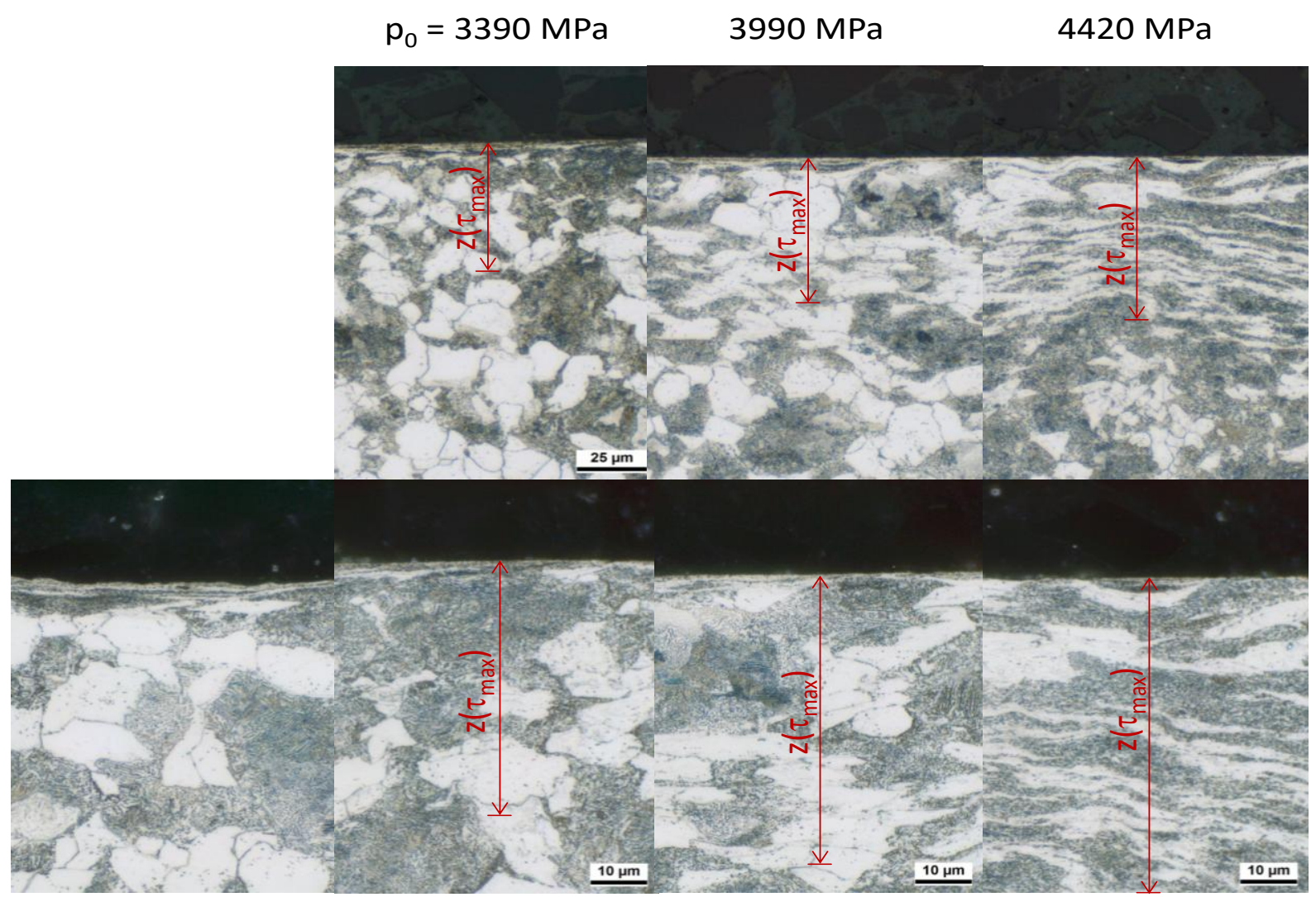

Figure 7: Co mparis on of metallographic cross sections of deep rolled tracks (steel 4820, FP-annealed), left: unaffected surface

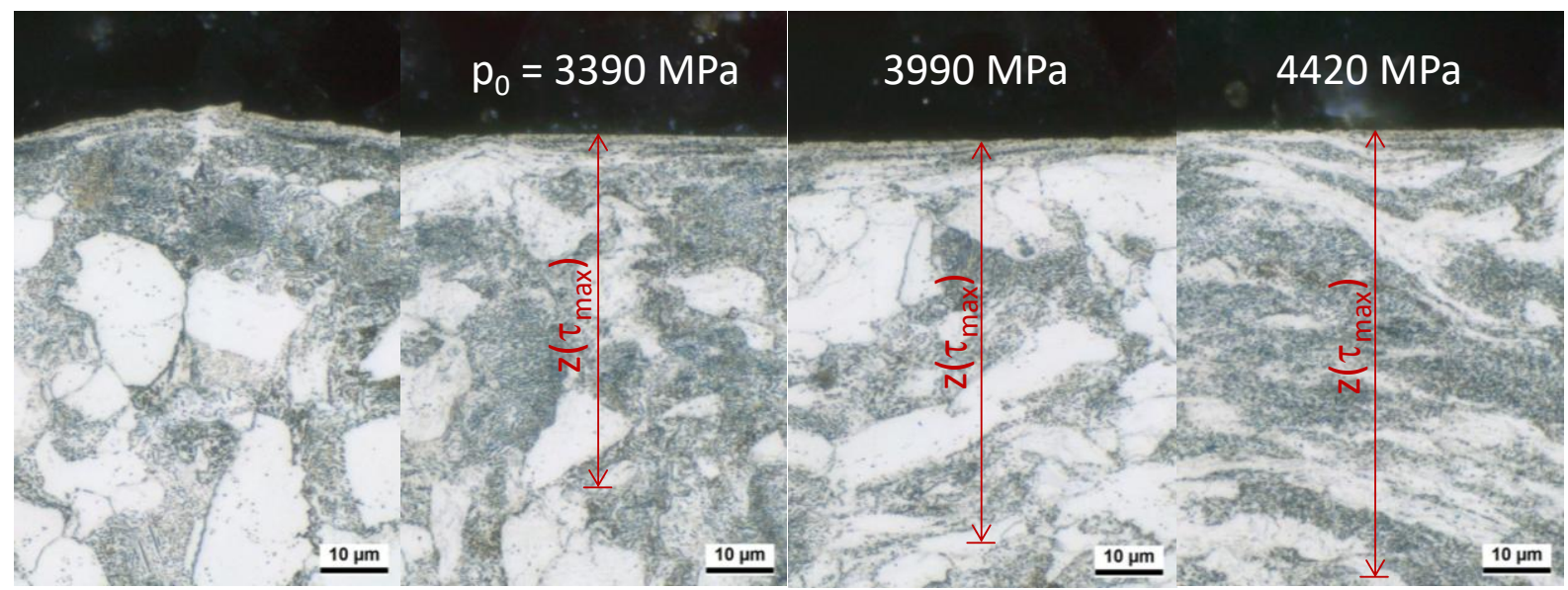

Figure 8: Comparison of metallographic cross sections of deep rolled surfaces (steel 4820, FP-annealed), tempered at $300{ }^{\circ} \mathrm{C}$, left: unaffected surface 


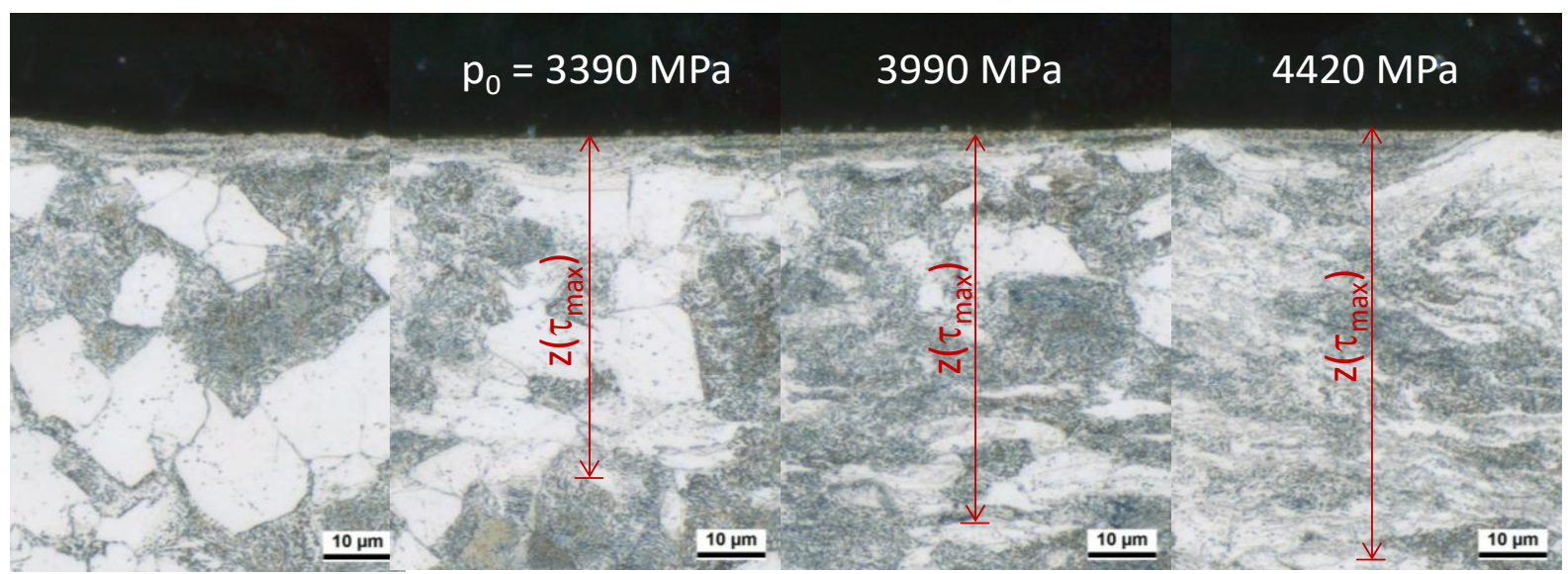

Figure 9: Comparison of metallographic cross sections of deep rolled surfaces (steel 4820, FP-annealed), tempered at $500{ }^{\circ} \mathrm{C}$, left: unaffected surface

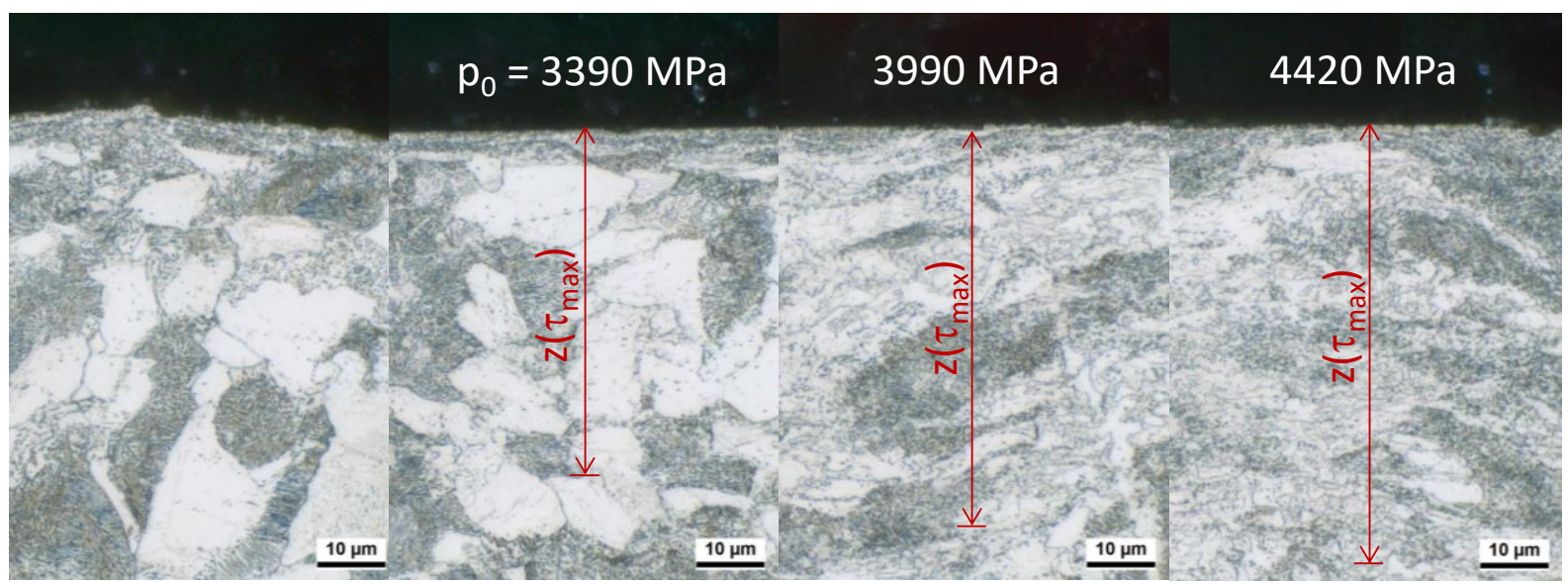

Figure 10: Co mparis on of metallographic cross sections of deep rolled surfaces (steel 4820, FP-annealed), tempered at $600{ }^{\circ} \mathrm{C}$, left: unaffected surface

At $700{ }^{\circ} \mathrm{C}$ the microstructure of the deep rolled track with a maximum contact pressure of $3390 \mathrm{MPa}$ shows small newly build grains at the depths of the maximum shear strength. Figure 11 shows that the size of newly build ferrite grains cannot be a one-to-one indicator for deformation.
In the ferritic regions of the samples very small new grains have built where the minimum deformation degree for the annealing temperature has been exceeded. In the pearlitic regions no grain refinement occurs.

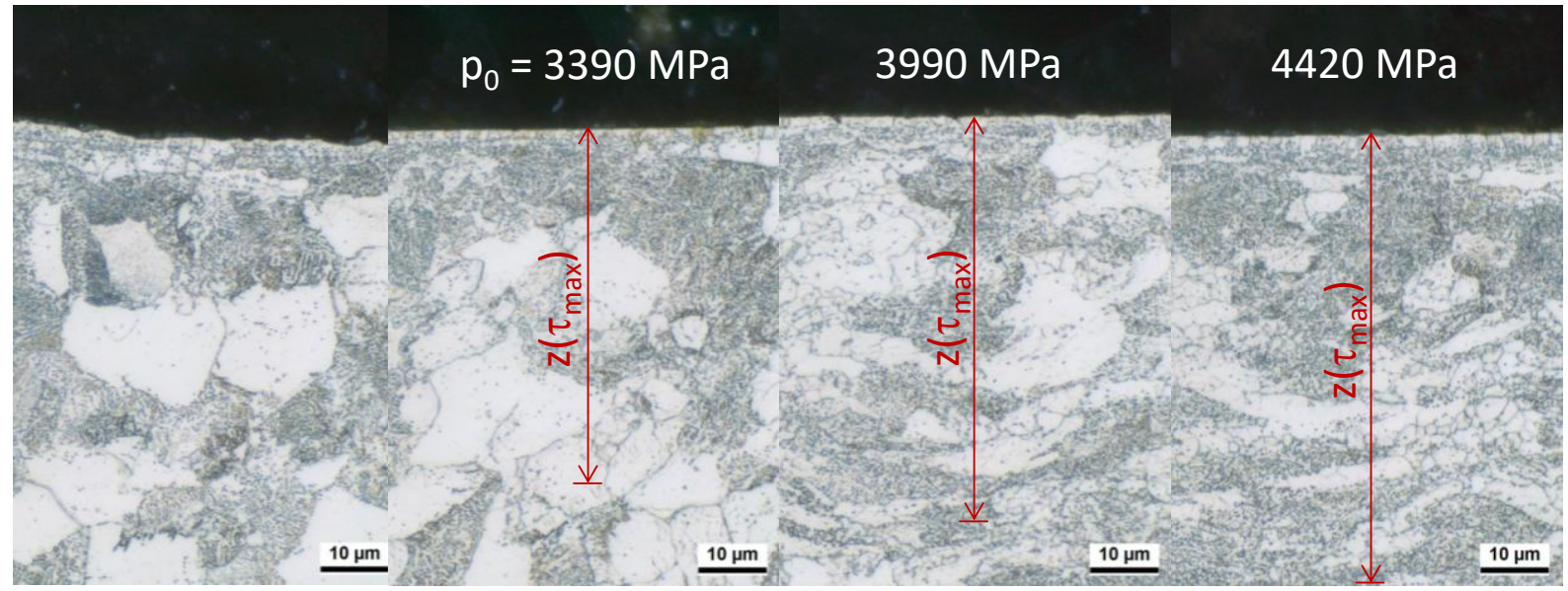

Figure 11: Comparis on of metallographic cross sections of deep rolled surfaces (steel 4820, FP-annealed), tempered at $700{ }^{\circ} \mathrm{C}$, left: unaffected surface 
After annealing at $800^{\circ} \mathrm{C}$ the microstructure shows no differences between deformed and not deformed regions (Figure 12). Due to the austenitization the microstructure is completely restored. The grains in the formerly deformed regions appear smaller than above and below. However, the differences are too small to excerpt an indicator fro $m$ these measures.

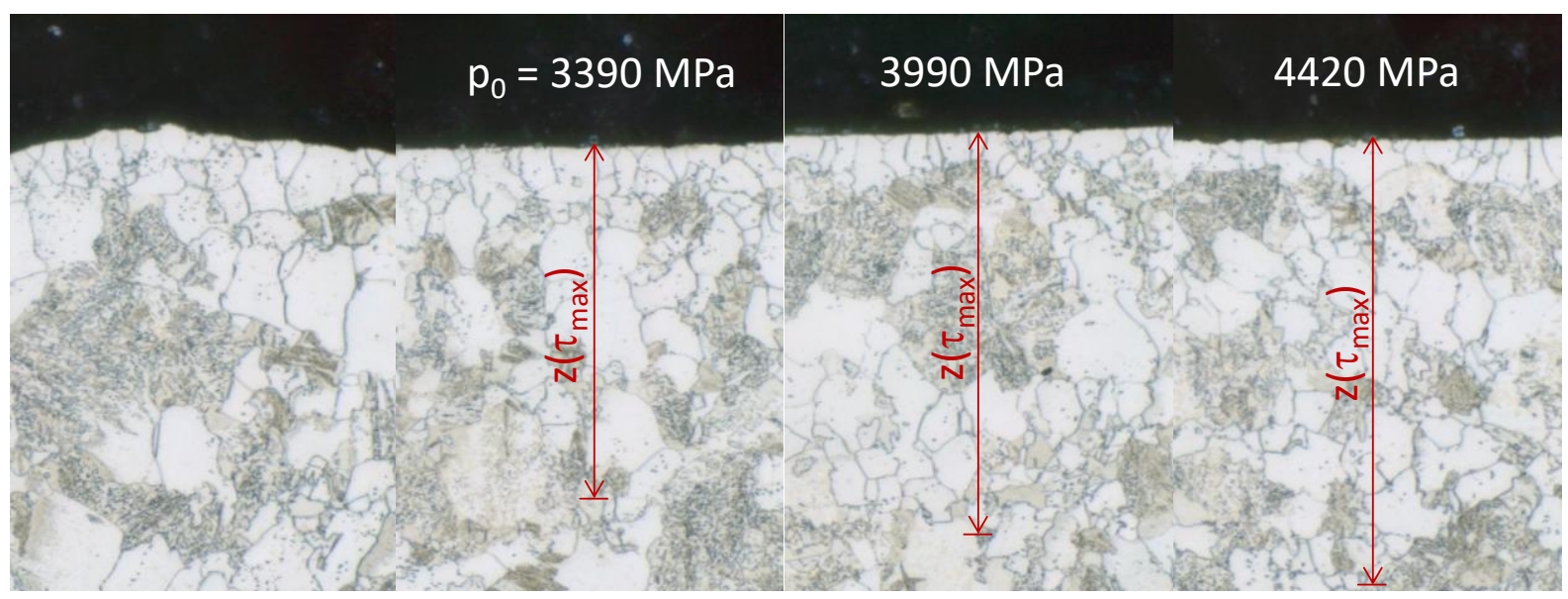

Figure 12: Comparis on of metallographic cross sections of deep rolled surfaces (steel 4820, FP-annealed), tempered at $800{ }^{\circ} \mathrm{C}$, left: unaffected surface

\section{Hardness measurement}

Figures 13, 14, and 15 show the diagrams of the hardness measurement results beneath the deep-rolling tracks on steel 4140 . The red line in all figures marks the depth where the calculated maximum shear stress appears. The Martens hardness of the bulk material of the AISI 4140 is about $2800 \mathrm{MPa}$. Figure 13 shows the hardness curve under the track with the maximum contact pressure of $3390 \mathrm{MPa}$. The curve has a maximum in a depth of about $15 \mu \mathrm{m}$ under the surface. The hardness at that point is about $3200 \mathrm{MPa}$. With further distance from the surface the hardness decreases to a minimum in a depth of 75 till $80 \mu \mathrm{m}$. Afterwards the hardness increases again slightly.

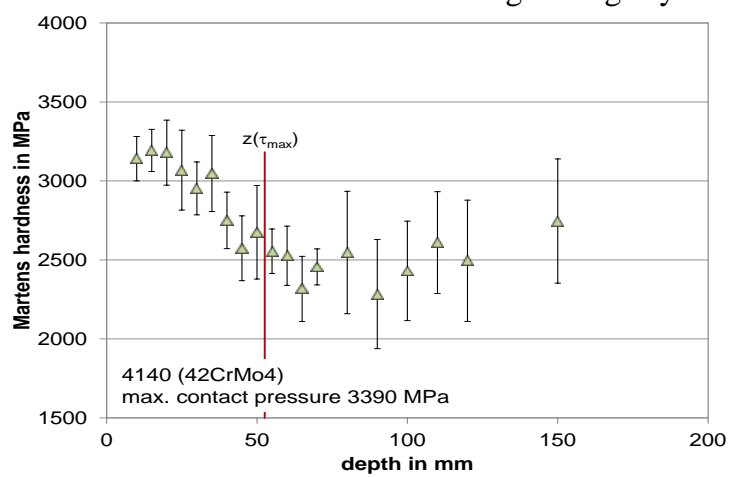

Figure 13: Hardness depth profile beneath the deep rolled surface (steel $4140 \mathrm{FP}$-annealed, max. contact pressure $3390 \mathrm{MPa}$ )
The resulting micro-hardness of the deeprolling process with a maximu m contact pressure of $3990 \mathrm{MPa}$ is depicted in figure 14. Again a maximu $m$ hardness is visible at a distance from the surface of about $40 \mu \mathrm{m}$. The hardness increases up to $2900 \mathrm{MPa}$. In between $40 \mu \mathrm{m}$ and $80 \mu \mathrm{m}$ the hardness decreases and reaches a minimum. Up to a depth of $150 \mu \mathrm{m}$ the hardness increases slightly.

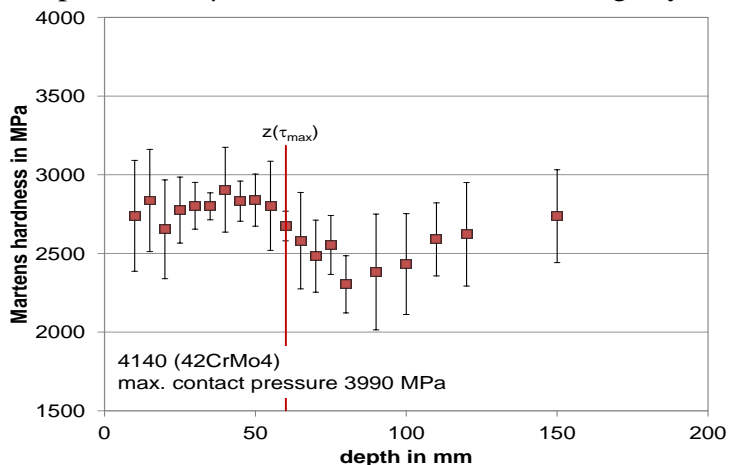

Figure 14: Hardness depth profile beneath the over rolled surface (steel $4140 \mathrm{FP}$-annealed, max. contact pressure $3990 \mathrm{MPa}$ )

Figure 15 shows the micro-hardness after a deep-rolling process with a maximum contact pressure of $4420 \mathrm{MPa}$. The course of the curve is similar to those depicted in figures 13 and 14 . There is a clear maximum of hardness in a distance from the surface of about $30 \mu \mathrm{m}$. The hardness reaches a value of $3000 \mathrm{MPa}$. With increasing distance from the surface the hardness decreases and hits a minimum in a depth of $80 \mu \mathrm{m}$. From the minimum on there is a slight increase in the hardness up to $2800 \mathrm{MPa}$ in $150 \mu \mathrm{m}$ depth. 


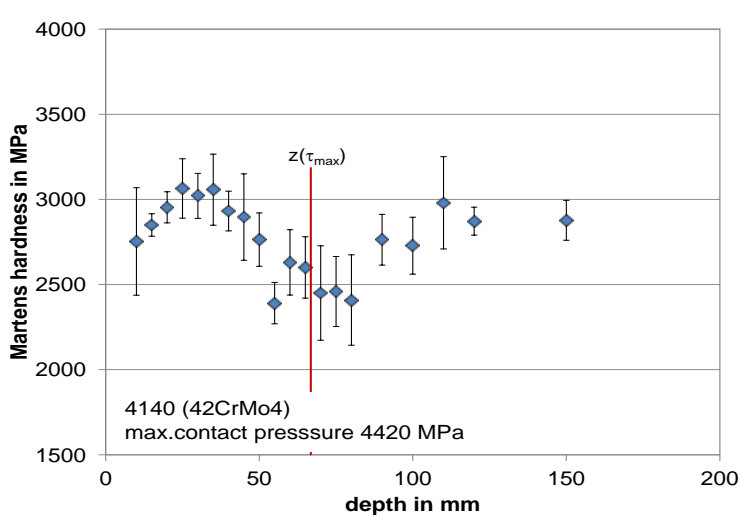

Figure 15: Hardness depth profile beneath the over rolled surface (steel $4140 \mathrm{FP}$-annealed, max. contact pressure $4420 \mathrm{MPa}$ )

Figures 16, 17, and 18 show the microhardness curves of the steel 4820 deep-rolled at three different pressures. The red line again resembles the depth of the appearance of the maximum shear stress. The bulk material without any surface modification has a hardness of about 2 $400 \mathrm{MPa}$. In figure 16 the micro-hardness development due to deep-rolling with a maximum contact pressure of $3390 \mathrm{MPa}$ is depicted. A slight increase of the hardness with increasing distance from the surface is visible. A possible maximu $m$ of hardness is found around $50 \mu \mathrm{m}$ from the surface. The hardness value goes up to almost $2800 \mathrm{MPa}$ at that point. Afterwards the hardness decreases slowly until it reaches the value of the bulk material.

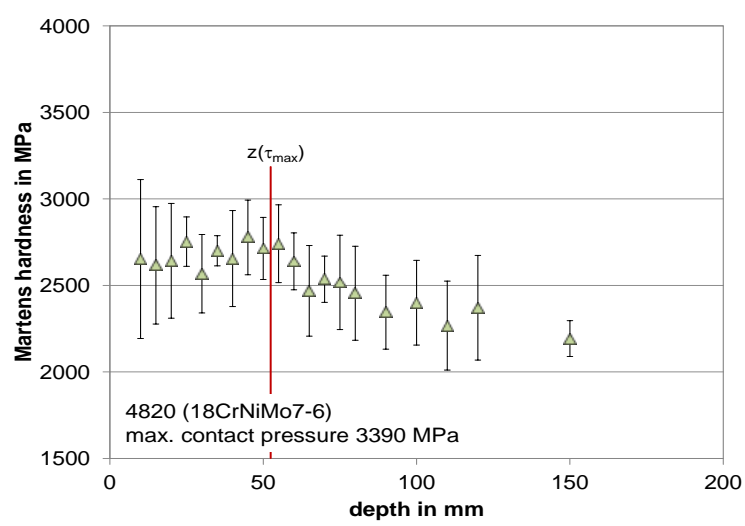

Figure 16: Hardness depth profile beneath the over rolled surface (steel $4820 \mathrm{FP}$-annealed, max. contact pressure $3390 \mathrm{MPa}$ )

The hardness measurement after deeprolling with a maximum contact pressure of 3990 $\mathrm{MPa}$ is shown in figure 17. A s mall trend in the hardness values is visible as a slight increase towards a maximum in about $60 \mu \mathrm{m}$ depth. At that distance from the surface the value of the hardness is $2900 \mathrm{MPa}$. With increasing depth the values decrease to the hardness level of the bulk material.

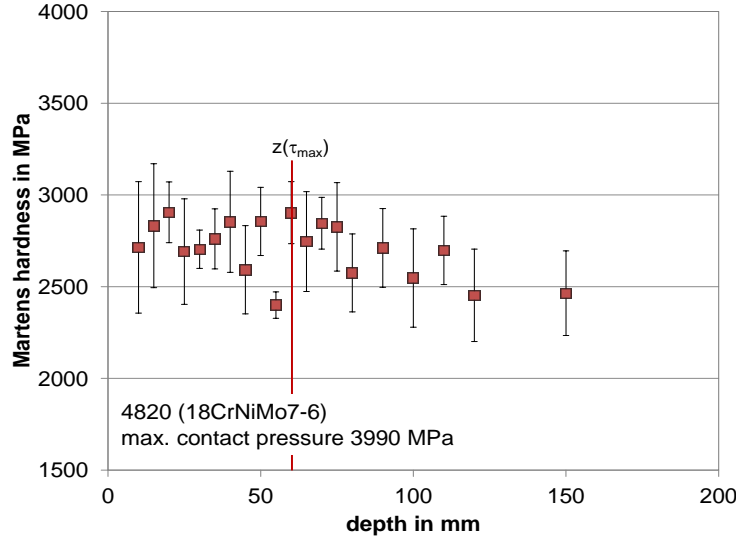

Figure 17: Hardness depth profile beneath the over rolled surface (steel $4820 \mathrm{FP}$-annealed, max. contact pressure $3990 \mathrm{MPa}$ )

The shape of the micro-hardness curve shown in figure 18 shows the strongest impact of the deep-rolling process. The maximum contact pressure in this case calculates to $4420 \mathrm{MPa}$. With increasing distance from the surface the hardness values clearly increase until they reach a maximum in a depth between $50 \mu \mathrm{m}$ and $60 \mu \mathrm{m}$. The hardness values reach up to $3400 \mathrm{MPa}$. The curve decreases again fro $m$ the maximu $m$ hardness.

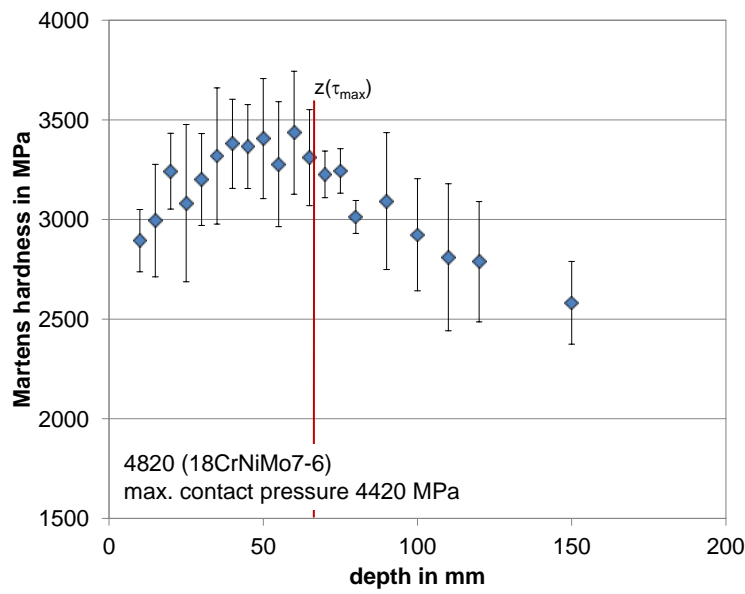

Figure 18: Hardness depth profile beneath the over rolled surface (steel 4820 FP-annealed, max. contact pressure $4420 \mathrm{MPa}$ )

\section{DISCUSSION}

The results of this investigation show that a quantified characterization of the surface region beneath a deep rolled track on the CRC standard steel 4140 is not possible with conventional microscopy. A subsequent recrystallization treatment generates a local grain refinement, but in the standard steel the effect is so small that the discovery of the newly build grains is no reliable measured variable. In the steel 4820 the effect is more pronounced. The deformation due to the deep 
rolling process increases up to the calculated depth of the maximum shear stress. Since the maximum deformation is expected at the depth of the maximum shear stress an additional friction effect can be assumed, since friction shifts the depth of the maximum shear stress to lesser depths. Still, a measure for the severity of the deformation cannot be extracted from the degree of recrystallization since the recrystallization effect occurs only in the ferritic structure fractions. In the pearlitic structure fractions the recrystallization is hindered by carbides. The recrystallized regions are therewith not definite.

The micro-hardness measurement in the standard steel does also not reveal the expected result in the standard steel grade. While the deep rolling of steel 4820 provokes with increasing pressure an increasing maximum in Martens hardness in a depth that may be assumed as depth of the maximum equivalent stress, the hardness results in the standard 4140 steel reveal a minimum in Martens hardness at this position. Lu [6] also observed a hardness decrease in deep rolled surface of 4140 steel with higher strength. In the same sample an increase of residual compressive stresses but a decrease in FWHW was measured in this region. $\mathrm{Lu}$ explained that fine distributed carbides may hinder the formation of dislocation cells, typical for deep rolled surfaces.

In the investigated microstructure the carbides are not finely distributed due to industrial production. Still, the presence of carbides seems to influence the steel's behavior in the deep roll process.

\section{CONCLUSIONS}

The results of this investigations show that it is not possible to reduce the investigation effort to characterize the surface state of machined samples within this project, since it would inevitably be related to loss in information needed to formulate the process signature for this process. The next step will be to investigate the dislocation and residual stress state of defined deformed and heat treated samples to develop the needed correlations.

\section{ACKNOWLEDGEMENTS}

The authors would like to thank the Company Ecoroll® for providing an "Ecoroll® testing device" to initiate locally defined deep rolling conditions.

Further the authors gratefully acknowledge the financial support of the research work by the German Research Foundation (DFG) within the transregional Collaborative Research Center SFB/TRR 136 "Process Signatures", sub project M02.

\section{REFERENCES}

[1]. MESYS A G: Calculation of contact stress. Online Tool for the calculation of Hertzian pressures for point or line contact. https://www.mesys.ch/?page_id=54

[2]. Vöhringer, O.: Relaxation of residual stresses by annealing or mechanical treatment. In: Advances in surface treatments, Vol. 4: International Guidebook on residual stresses, Ed.: Niku Lari, A., Pergamon Press (1987)

[3]. Hertz, H. R.: Über die Berührung elastischer Körper (On Contact Between Elastic Bodies), in Gesammelte Werke (Collected Works), Vol. 1, Leipzig, Germany (1895)

[4]. Föppl, L.: Der Spannungszustand und die Anstrengung des Werkstoffes bei Berührung zweier Körper. Forsch. Ing. Wes. 7 (1936), 210-215

[5]. Altenberger ,I. : Mikrostrukturelle Untersuchungen mechanisch randschichtverfestigter Bereiche schwingend beanspruchter metallischer Werkstoffe, Dissertation, Universität Gesamthochschule Kassel (2000)

[6]. Lu, H., Scholtes, B.; Macherauch, E.: Randschichtzustände von normalisiertem und vergütetem 42CrMo4 nach konsekutiven Kugelstrahl- und Festwalzbehandlungen.

Materialwis senschaften und

Werks tofftechnik 23 (1992), pp. 388-394

[7]. Hoffmann, F.: Mikrostruktur und Schwingfestigkeit von $\mathrm{Ck} 45$ nach kombinierter mechanischer und thermoche mischer

Randschichtverfestigung.

VDI-

Fortschrittberichte, Reihe 5: Grund- und Werkstoffe Nr.123, VDI-Verlag, Düsseldorf (1987).

[8]. Kloos, K.-H.; Adelmann, J.: Schwingfestigkeitssteigerung durch Festwalzen. Materialwis senschaften und Werkstofftechnik 19 (1988), pp. 15-23 